\title{
Sacralidad y funcionalidad del arco en Filoctetes de Sófocles
}

Function and Sacrality of Philoctetes' Bow

Fernando Pérez Lambás*

Universitat de València, España

fernando.perez@uv.es

\section{Resumen:}

El arco de Filoctetes, como objeto simbólico importante y sagrado de la tragedia homónima de Sófocles, ha sido estudiado en numerosas ocasiones. A pesar de ello, su importancia como arma sagrada merece una revisión que atienda a los contextos religioso y épico de los que bebió Sófocles. Según la teoría tradicional, esta sacralidad deriva de la proveniencia divina del arco, que procede de Heracles. Con todo, en algunos pasajes podría explicarse mejor por la importancia que, en determinados contextos religiosos, adquirían ciertos objetos venerables que eran considerados también sagrados.

Palabras clave: Sófocles, Filoctetes, Armas, Arco.

\section{Abstract:}

The bow of Philoctetes, as a symbolic and sacred object, has been studied many times. However, its importance as a sacred weapon deserves a revision regarding the religious and epic contexts of the author. According to the general view, this sacred quality comes from the divine provenience of the bow, which belonged to Heracles. Nevertheless, in some passages it could be best explained by the sacred significance that some objects had in certain religious contexts.

KEYwOrDs: Sophocles, Philoctetes, Weapons, Bow.

\section{El SIMBOLISMO DEL ARCO: PERSPECTIVAS Y ENFOQUES}

Muchas tragedias de Sófocles presentan un objeto simbólico principal que concentra la visión del espectáculo teatral (Segal, 1980, p. 125). Así, la espada, en Áyax, es un objeto simbólico que refleja la destrucción o, mejor dicho, la transformación de la condición heroica de Áyax. ${ }^{1}$ Su espada, símbolo de fuerza heroica, es el mismo instrumento del que se sirve para matar el ganado, enloquecido por la diosa Atenea, y para suicidarse (Sófocles, Ayax 30, 828). Otros símbolos visuales de tragedias son el vestido manchado de sangre del centauro Neso que, en Traquinias (758-771), causa la muerte de Heracles o la urna que contiene las supuestas cenizas de Orestes en Electra (1126-1127), símbolo de reconocimiento entre los hermanos y objeto personificado que guarda el recuerdo de Orestes.

En la tragedia Filoctetes de Sófocles, el arco es el objeto simbólico más destacable, pues representa las características de su portador y entra en el juego dramático (Segal, 1980, pp. 125-126; Taplin, 2003, pp. 89-93; Fletcher, 2013, pp. 202). En este sentido, aunque el adivino Héleno había vaticinado que debían llevar a Troya a Filoctetes para poder saquear la fortaleza de Príamo (610-613), Odiseo llega a la isla de Lemnos, junto con Neoptólemo, para arrebatar el arco a su dueño en la idea de que solo con este objeto podrán devastar la ciudad de Troya. ${ }^{2}$ El juego dramático se crea en el momento en el que Odiseo, rico en ardides, trama un engaño con el fin de despojar a Filoctetes del arco, objeto importante en la medida en que, para Odiseo, es el único medio de obtener la victoria en Troya, a pesar de la discordante predicción del adivino (Knox, 1964, pp. 127; Hinds, 1967, p. 171; Gill, 1980, p. 140; Segal, 2013, p.146; Easterling, 1978, p. 27).

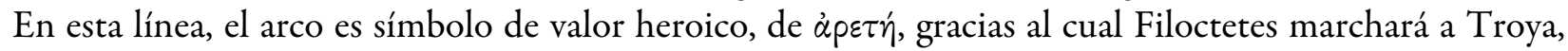
matará a Paris y destruirá la ciudad de Príamo. ${ }^{3}$ Este simbolismo heroico, que deriva de Heracles, se encuentra presente en esta tragedia. ${ }^{4}$ Pero al mismo tiempo, en el arco se refleja la lealtad y la confianza entre los personajes. Si Filoctetes recibió el arco de Heracles en compensación por haber hecho el favor de incendiarlo

Recepción: 7 de febrero de 2019 | Aceptación: 15 de mayo de 2019 | Publicación: 28 de octubre de 2019 
en la pira, Neoptólemo lo recoge a su vez como muestra de la confianza que ha adquirido con Filoctetes, que le cede el arco en agradecimiento por la promesa de llevarlo de vuelta a casa (667-670, 776-778, 801-803). De este modo, Filoctetes confía en la palabra engañosa de Neoptólemo y accede a entregarle su arma más valiosa. El arco, por tanto, es al mismo tiempo símbolo de hazaña heroica y de amistad auténtica y recíproca (Gill, 1980, p. 138; Taplin, 2003, p. 90; Harsh, 1960, pp. 412-413; Fletcher, 2011, p. 89; Austin, 2011, pp. 103-104).

Según Segal (1999, pp. 294-295), el arco es también un símbolo de civilización que refleja la ambigüedad del personaje Filoctetes, como un ser salvaje y humano al mismo tiempo. Este arco no solo es mencionado

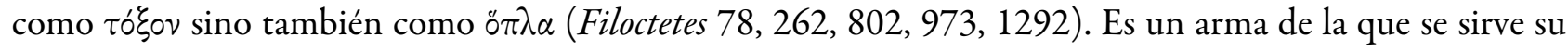
dueño tanto para protegerse de los enemigos como para cazar a los animales salvajes con los que convive y proporcionarse alimento, como harían los seres humanos (75-78, 104-105, 162-168, 287-290). De este modo, Filoctetes no queda inerme ante las fieras y puede servirse de su arma para procurarse el alimento necesario para subsistir (Segal, 1976, pp. 76-77; Fletcher, 2013, p. 203).

Este planteamiento, según Lasso de la Vega (2003, p. 171), podría parecer antiheroico en la medida en que se utiliza un arma destinada a un uso bélico y glorioso como medio para alimentarse en una cueva aislada de la sociedad. En este sentido, como sustento de la vida del personaje, el arco es utilizado por su dueño para procurarse víveres y mantener una existencia salvaje como cazador solitario en una caverna (Biggs, 1966, p. 232; Segal, 1999, p. 295; Mauduit, 1995, p. 357), ${ }^{5}$ un hecho que convierte al personaje en un depredador cuyas carencias de normas sociales lo asimilan a las mismas bestias que caza y que ahora lo cazarán a él (Filoctetes 955-958). Esta imagen, entre otros factores, refleja un personaje asilvestrado, salvaje y relegado de la sociedad, pues el hombre que cazaba se ha convertido en el animal cazado. ${ }^{6}$

La importancia del arco reside también en el hecho de ser el centro de visión donde convergen todas las miradas en diversos pasajes de la tragedia: "Neoptolemus' close look, as he accepts it in his hands (Phil. 776) 'theatricalises' the object by converting it into a dramatic spectacle, a thea" (Lada-Richards, 1997, p. 179). El arco es, por tanto, el objeto que concentra la ő $\psi$ is característica del espectáculo teatral. ${ }^{7}$ Aunque la alusión al arco es recurrente en toda la tragedia, esta concentración de visión se produce especialmente en momentos en los que el arma aparece relacionada con lo sagrado. En estos pasajes el espectáculo teatral se caracteriza por la visión destacada del arco como objeto simbólico que llena de ritualidad la representación.

Estos momentos hacen referencia principalmente a cuatro pasajes en los que el arma, como símbolo de confianza entre los personajes, es cogida con las manos, recibida y reverenciada como objeto sagrado y venerable, según las evocaciones gestuales presentes en la obra. En dos de estos instantes el arco aparece

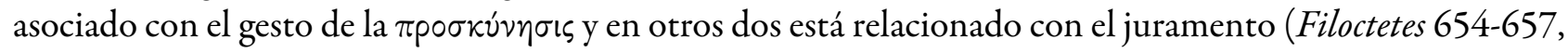
776-778, 941-943, 1286-1292).

La relación del arco con lo sagrado nos lleva a preguntarnos por el origen de esta sacralidad. Según la teoría tradicional, el arco es sagrado porque proviene de Heracles, que a su vez lo recibió de Apolo. ${ }^{8} \mathrm{Su}$ procedencia divina estaría justificando, por tanto, su naturaleza sagrada. ${ }^{9}$ De este modo, en el arco se presenta la fuerza sobrehumana de Heracles como algo inherente al arma misma, razón por la cual no es arbitrario que se precise de este objeto para conquistar Troya ni que sea Heracles quien al final de la tragedia prediga este destino. El arco cumpliría con su función vaticinada como arma saqueadora de la ciudadela troyana. Desde esta perspectiva, la sacralidad del arco resulta obvia, pues las relaciones entre el arco y Heracles son tan fuertes que el arma participa de la misma sacralidad y valor heroico que su anterior poseedor.

Si bien es verdad que el arco es principalmente sagrado por su relación con Heracles, en los pasajes en los que aparece como objeto visual especial podríamos también encontrar una explicación que derive, por un lado, de la tradición épica del arco, según la cual este se concebía como un arma gloriosa asociada con lo divino como emblema representativo del guerrero, y, por otro lado, del contexto religioso de la época, tradiciones que no serían ajenas ni al espectador ni al propio Sófocles. Según nuestra interpretación, el arco podría ser 
sagrado a causa de la concepción religiosa según la cual determinados objetos, especialmente las armas que estaban vinculadas a los guerreros, eran símbolos sagrados que debían ser venerados o aparecían asociados con lo divino. En concreto, analizamos los cuatro pasajes en los que, según creemos, aparece el arco como objeto visual destacado en directa relación con lo sagrado, con el fin de aportar algunos datos que nos puedan ayudar a comprender mejor la relación del arma con la tradición épica y el contexto religioso del autor.

\section{EL ARCO: OBJETO GLORIOSO Y VENERABLE}

Casi al final del primer episodio, cuando Filoctetes y Neoptólemo se entretienen más de lo esperable, aparece el žutopos con la finalidad de hacer avanzar la acción, pues ya Odiseo en el prólogo anunció que enviaría al comerciante si se demoraban demasiado (126-129, 542 y ss.). Con el objetivo de acelerar la partida de Filoctetes y Neoptólemo, el comerciante les informa que Odiseo y Diomedes se encuentran de camino para llevarse consigo al hijo de Peante, dado que el oráculo de Héleno ha vaticinado que solo con su presencia se puede conquistar Troya (591-613).

Al oír estas palabras, el hijo de Peante y el de Aquiles precipitan su marcha, no sin antes recoger aquellos aparejos que Filoctetes vaya a necesitar. Tras tomar las hojas que le sirven para aliviar el dolor de su herida, se percata del arco que, para evitar que caiga en manos ajenas, pretende también llevarse consigo (652-653). Esta es la primera vez que Neoptólemo contempla el arma que debe capturar. En los versos siguientes, el arco aparece como objeto que concentra la visión de los personajes y provoca en Neoptólemo una reacción de respeto religioso y veneración centralizada en un objeto simbólico divinizado:

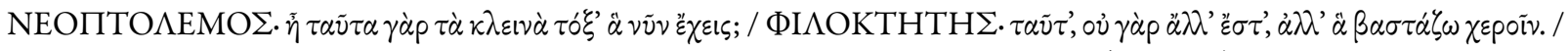

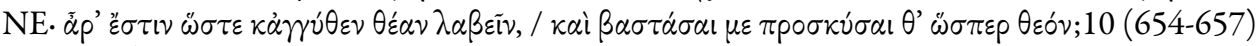

NEOPTÓLEMO: ¿Este que ahora tienes es el glorioso arco? FILOCTETES: Este mismo, y no es otro sino el que sostengo en mis manos. NE: ¿ ¿Me es posible verlo de cerca, agarrarlo y adorarlo como a un dios?

La aparición del arco, calificada por Austin (2011, p. 105) como una epifanía, crea un ambiente de sacralidad que ritualiza la representación. En este pasaje hay dos aspectos que debemos estudiar por separado: por un lado, la calificación $\kappa \lambda \varepsilon ı \nu \alpha ́$ y su relación con la tradición épica y religiosa de Sófocles, y, por otro lado, el momento de ritualidad en el que Neoptólemo pregunta, con respetuosidad religiosa, si le es posible contemplar de cerca y sostener el arco con sus manos.

El primer epíteto que recibe el arco en estos versos, $\kappa \lambda \varepsilon \imath \alpha_{\alpha}$, está cargado de resonancias épicas (Schein, 2014, p. 225), pues el objeto es calificado como un arma gloriosa e ilustre, una denominación que parece estar anticipando la función del arma en la guerra de Troya. Neoptólemo, la primera vez que contempla el arco, lo recibe de un modo majestuoso y solemne, una manera de concentrar la atención en la importancia del arco como un arma guerrera y heroica.

Pero al mismo tiempo, la calificación del arco como un objeto célebre recuerda la presentación que

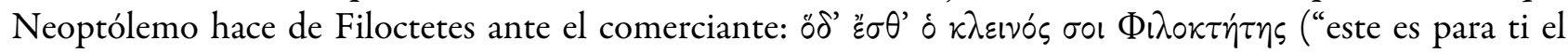
glorioso Filoctetes", 575). Esta presentación trae a la mente la primera aparición de Filoctetes en escena, en la que el hijo de Peante se presenta ante Neoptólemo como el famoso dueño de las armas de Heracles: ¿ $\delta$ ' $\varepsilon \not \mu$ ' hayas oído que es el dueño de las armas de Heracles", 261-262).

Estas reminiscencias de pasajes anteriores conectan el arco con su actual dueño Filoctetes y presagian la función gloriosa que tanto el personaje como su arma tendrán en la guerra de Troya, pues ambos reciben el mismo epíteto. La relación entre el guerrero y su arma, objeto gracias al cual el héroe es un personaje ilustre que combate en la guerra, es frecuente también en los poemas homéricos, donde héroes como Diomedes,

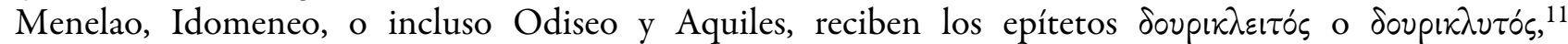
compuestos fácilmente comprensibles como aquellos guerreros "célebres por su lanza" 12 
La relación entre el guerrero y su arma es una constante en la tradición épica y religiosa de la que parte Sófocles. En esta línea, la alusión a Heracles y a las armas en la primera presentación de Filoctetes insiste en la sacralidad que rodea este objeto y asocia la figura del dios con la de Filoctetes en una relación simbolizada por el arma. Esta vinculación del objeto con la guerra y con la divinidad hace que el mismo arco sea calificado

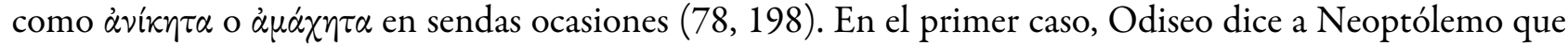

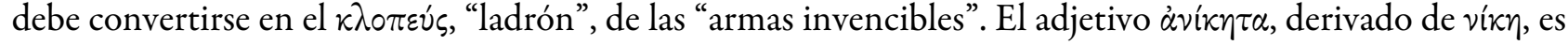
relevante como calificador de estas armas, pues anticipa la función victoriosa del arco en la guerra de Troya.

En el segundo caso se mencionan las flechas invencibles de los dioses, $\tau \dot{\alpha} \theta \varepsilon \tilde{\omega} \nu \dot{\alpha} \mu \dot{\alpha} \chi \eta \tau \alpha \beta \varepsilon \dot{\varepsilon} \eta$, cuya función guerrera aparece marcada por el epíteto $\dot{\alpha} \mu \alpha ́ \chi \eta \tau \alpha$, derivado de $\mu \alpha \dot{\alpha} \chi \eta$. Así también, la dependencia sintáctica del genitivo $\theta \varepsilon \tilde{\omega} \nu$ con respecto al sustantivo $\beta \varepsilon \lambda \eta$ subraya la naturaleza divina del arma, que proviene de Heracles y cuya genealogía se remonta al dios Apolo. ${ }^{13}$ De hecho, en los poemas homéricos esta divinidad recibe el

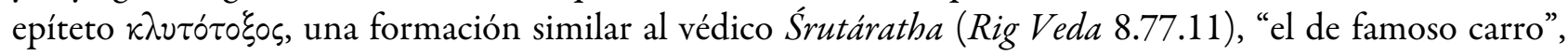
un epíteto tradicional del dios Indra que demuestra la importante conexión en las culturas clásicas entre las armas, los héroes y las divinidades (West, 2007, p. 460). ${ }^{14}$

El estrecho vínculo entre las armas, la guerra y los dioses aparece atestiguado en otros ejemplos de los poemas homéricos. A este respecto, no podemos dejar de mencionar el ilustre escudo de Aquiles fabricado por Hefesto, el escudo de Áyax construido por el mítico herrero Tiquio o el cetro de Agamenón que forjó también el dios Hefesto, así como la multitud de armas forjadas por el dios herrero (Ilíada II.101-108, VII.220, XVIII.478-608). Muchas de ellas son armas defensivas de guerreros que lucharon en Troya cuyo simbolismo heroico es indisociable de su naturaleza divina. Otras son herramientas armamentísticas pertenecientes a los dioses, como la égida y los rayos de Zeus, el arco y las flechas de Eros o el casco de Hades. Incluso en muchas otras culturas el arma del guerrero se llega a divinizar o es forjada por los dioses, como el martillo de Thor entre los nórdicos o el dios de la guerra adorado en forma de cimitarra entre los escitas. ${ }^{15}$ Así, el arco de Filoctetes, proveniente de los dioses, forma parte de una tradición épica que lo conecta con el héroe guerrero y con las divinidades, como aparece atestiguado tanto en el mundo griego como en otras culturas antiguas. En esta línea, Filoctetes posee un arco glorioso no solo por sus características épicas, un instrumento imprescindible para luchar en la guerra contra Troya, sino también por su conexión con lo divino.

En el pasaje que analizamos, Neoptólemo pregunta a Filoctetes, con cierto asombro reverencial y religioso, si le es posible contemplar de cerca el arco, sostenerlo en sus manos y reverenciarlo como a un dios. Estos tres aspectos marcan un protocolo ritual perfectamente formalizado y adaptado al contexto de veneración de un objeto sagrado. Tras esta pregunta, Filoctetes evidencia que las palabras mencionadas por Neoptólemo son

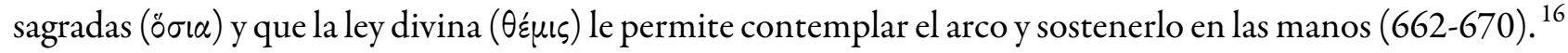

El diálogo mantenido entre ambos personajes evoca por primera vez un ritual muy conocido entre los griegos. La concesión del arco como objeto simbólico importante puede estar reproduciendo los actos que se realizaban en el ritual de la $\xi \varepsilon v i ́ \alpha$, durante el cual se sellaba un pacto de fidelidad y amistad por medio del intercambio de regalos, llamados $\pi \iota \sigma \tau \dot{\alpha}$, y del estrechamiento de manos, gesto que se mencionará

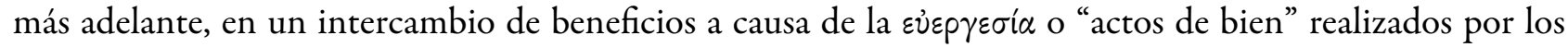
participantes en el ritual. ${ }^{17}$ Como garantía de esta fidelidad, se ofrecía a la otra persona un objeto simbólico especial. En esta línea, los guerreros otorgaban sus armas como intercambio de bienes en el momento en que se disponían a sellar pactos de tregua ante las hostilidades (Kaimio, 1988, p. 26). Un ejemplo lo encontramos en el intercambio de regalos que protagonizaron Áyax y Héctor con el fin de acabar con la lucha que mantenían, a causa de lo cual Héctor fue llamado ל́svos por Áyax (Homero, Ilíada VII.303 y ss.; Sófocles, Áyax 817).

Por otra parte, como sucede con frecuencia en la tragedia griega, en el pasaje que comentamos no encontramos una ejemplificación directa del ritual de la $\xi \varepsilon v i ́ \alpha$, sino más bien una evocación que recuerda este ritual. De hecho, Neoptólemo solo pregunta si puede seguir los pasos de este rito y Filoctetes responde que le es posible realizarlo. De este modo, como afirma Belfiore (2000, p. 69), "here, as often in tragedy, 
the poet adapts ritual patterns for dramatic purposes". Desde el primer momento, Neoptólemo entró en contacto con Filoctetes con el fin de robarle el arco, para lo cual puso en práctica la estratagema ideada por Odiseo según la cual debía trabar una férrea amistad con su adversario. Cuando el hijo de Aquiles le promete fidelidad y ayuda en su partida, Filoctetes, que guardaba un fuerte rencor a los griegos que lo abandonaron y

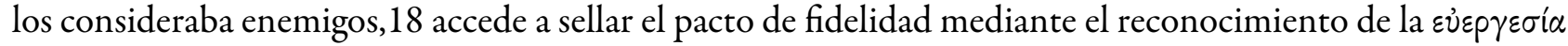

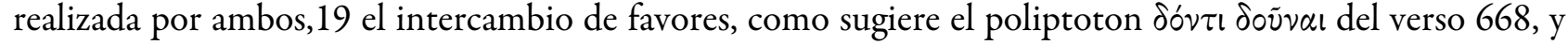
el pacto sellado mediante el contacto físico con el objeto simbólico más preciado. El arco, como símbolo de amistad y confianza entre los personajes, es el arma ofrecida como intercambio recíproco de beneficios. 20

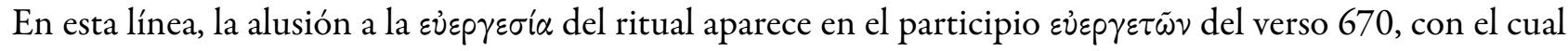
Filoctetes se refiere al motivo por el que él mismo selló una relación de amistad con Heracles cuando accedió a incendiarle en la pira, en compensación por lo cual recibió el aclamado arco (Knox, 1964, p. 139; Belfiore, 2000, p. 68; Gill, 1980, p. 138; Kosak, 1999, p. 119). De nuevo, esta amistad ritualizada se encuentra presente en la relación pactada entre Neoptólemo y Filoctetes, que se formalizará posteriormente con el contacto físico con el arma.

Con todo, a diferencia del ritual, en la tragedia no se produce un verdadero intercambio, pues solo se ofrece el regalo en una dirección, mientras que el hijo de Aquiles solo promete sacar a Filoctetes de la isla (526-529). Igualmente, en estos versos Neoptólemo todavía no ha tocado el arco, como indican los futuros de los versos 659 y 667 , pero las referencias textuales aluden a un acto ritualizado que se ejecutará más adelante. Aunque el ritual de la $\xi \varepsilon v i ́ \alpha$ no se realiza en ningún momento, el registro lingüístico y las evocaciones de este diálogo recrean en la mente del espectador un formalismo que el público conocía bastante bien y que, en el pasaje analizado, es empleado con fines efectistas y dramáticos.

Tras la alusión a la contemplación y al contacto físico con el arma, Neoptólemo evoca un acto ritual

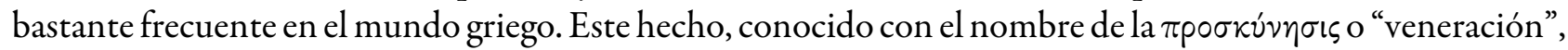
deja claro que el arco es divinizado. Comparando el arma con una divinidad ( $\omega \sigma \pi \varepsilon p \theta \varepsilon o ́ v)$, el hijo de Aquiles solicita realizar una reverencia y alude a un gesto ritual que se realizaba con frecuencia como saludo ante las imágenes de los dioses o en contextos religiosos de subordinación o adoración ante la divinidad, como las

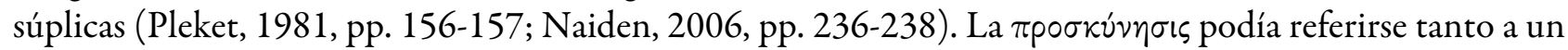
gesto de reverencia ante la imagen del dios como al acto de besarla (Schein, 2014, p. 225). ${ }^{21}$

Debido a la ambivalencia de significados que abarca el verbo $\pi \rho \circ \sigma \kappa v ́ \sigma \alpha l$, como mencionan los comentarios, resulta complicada la traducción, pues puede significar tanto "reverenciar el arco" como "besarlo" o simplemente "venerarlo con palabras" (Schein, 2014, p. 225; Avezzù, Pucci \& Cerri, 2003, pp. 238-239). A este respecto, tanto Webster (1970, p. 108) como Jebb (1898, p. 109) ponen en relación la reverencia solicitada por Neoptólemo con la que realizaban los jóvenes soldados en honor de sus ilustres armas. Es el caso de Partenopeo, un guerrero arcadio que, en su lucha contra los tebanos, jura por su lanza, a la que el héroe reverencia más que a un dios (Esquilo, Los siete contra Tebas 529). También el argonauta Idas llega a jurar por su lanza impetuosa, gracias a la cual obtiene una gloria mayor que los demás ( $\alpha \lambda \omega \omega \nu \kappa \tilde{\delta} \delta \varsigma$, Apolonio de Rodas I.466-468). Estas nuevas referencias a las armas de los guerreros, como símbolos sagrados y gloriosos por los que se realiza el juramento, recuerdan nuevamente la importancia de la sacralidad de las armas, asociadas con la guerra, los héroes y la divinidad. Por estos motivos, el arma adquiere cierto carácter sacro a causa del cual debe ser reverenciada igual que los dioses. ${ }^{22}$

Por otra parte, tanto Kamerbeek (1980, p. 102) como Schein (2014, p. 225) piensan que Neoptólemo, que en estos momentos está poniendo en práctica los planes de Odiseo, utiliza estas palabras al servicio del engaño. De este modo, sus fraudulentas palabras estarían traicionando la sacralidad del arco. En nuestra opinión, como piensa Austin (2011, pp. 106-107), las palabras que en este momento menciona Neoptólemo no llegan a traicionar la sacralidad del objeto, pues el héroe simplemente reconoce esta sacralidad y solicita, con respeto y veneración, el reconocimiento del poseedor para sostenerlo entre las manos, tomando precauciones para no influir en su santidad. ${ }^{23}$ Con ello, se pone el énfasis en la emoción sentida por el personaje ante la presencia de 
un objeto sagrado como el arco. Es más bien la estratagema en sí, los medios empleados, los que se desvelarán como fraudulentos en un momento posterior, en el cual el hijo de Aquiles se revelará como transgresor de las normas sagradas que no podía infringir ni ante el arco ni ante Filoctetes.

El pasaje analizado prepara al espectador para los versos siguientes, en los cuales Neoptólemo coge con sus manos el arco. Tras una exigua intervención del coro, Filoctetes se detiene por su herida y cede el arma al hijo de Aquiles, con el fin de que este la custodie por un momento hasta calmar la herida con el sueño (763-777). A su vez, Neoptólemo promete a Filoctetes no abandonarlo mientras duerme (809-812). Con las palabras que reproducimos a continuación, Filoctetes cede el arco a Neoptólemo y este objeto se vuelve a convertir en el símbolo visual más llamativo:

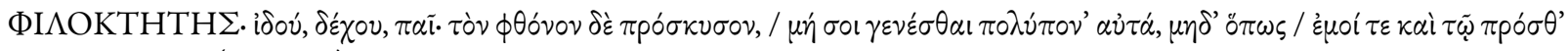

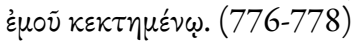

FILOCTETES: ¡Ea! Recíbelo, hijo: reverencia la envidia, no vaya a ser que tengas los mismos sufrimientos que yo y que el que lo tuvo antes que yo.

En el momento en el que Filoctetes tiende la mano para ceder el arco a Neoptólemo, pronuncia unas palabras que recuerdan el instante de reverencia anterior, que el hijo de Aquiles solicitaba ante el arco. El

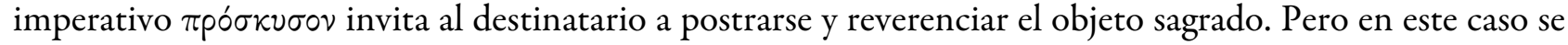
alude a la envidia de los dioses como elemento receptor de la reverencia. A este respecto, Schein (2014, pp. 241-242) informa que, en el siglo $\mathrm{V}$ a. C., la envidia ( $\phi$ Oóvos) a menudo se refería a la tendencia de los dioses a restringir o castigar la prosperidad de aquellos humanos que parecían estar por encima de los límites que les correspondían. Para alejar esta "envidia divina”, los hombres empleaban palabras o gestos apotropaicos. ${ }^{24}$

En la expresión empleada por Filoctetes, el personaje alude al hecho de que sus propios sufrimientos son consecuencia de la envidia de los dioses, derivada de la posesión de un arma sagrada, que implica un exceso en la proporción y el comedimiento esperable en los humanos. Con estas palabras, por tanto, Filoctetes indica a Neoptólemo que va a recibir un objeto que se encuentra muy por encima del alcance humano, pues se trata de un arma sagrada cuya posesión puede provocar la envidia de los dioses. Por ello, el mismo Filoctetes toma precauciones al afirmar que Neoptólemo debe ser cauto recibiendo un objeto tan sagrado y venerable, "no vaya a ser que tenga los mismos sufrimientos ( $\pi \circ \lambda \nu ́ \pi \circ v$ ' $\alpha \dot{\tau} \tau \dot{\alpha})$ ” que su actual poseedor y que Heracles. ${ }^{25}$ De este modo, se enfatiza la sacralidad del objeto de una manera bastante compacta y expresiva que pone de manifiesto una sacralidad que sobreexcede la naturaleza humana.

En el instante en el que Neoptólemo contempla el arco y lo sostiene definitivamente en las manos, deja de ser el joven al servicio de las aspiraciones personales de Odiseo y sella un pacto sagrado e inamovible de fidelidad con Filoctetes. La sacralidad del arco juega un importante papel simbólico que se manifiesta por medio del contacto físico con un arma sagrada en sí misma.

\section{El JURAMENTO, LAS ARMAS y LA AMistad RitUALiZADa}

Con las siguientes palabras explica Filoctetes la traición que Neoptólemo ha cometido incumpliendo la palabra prometida:

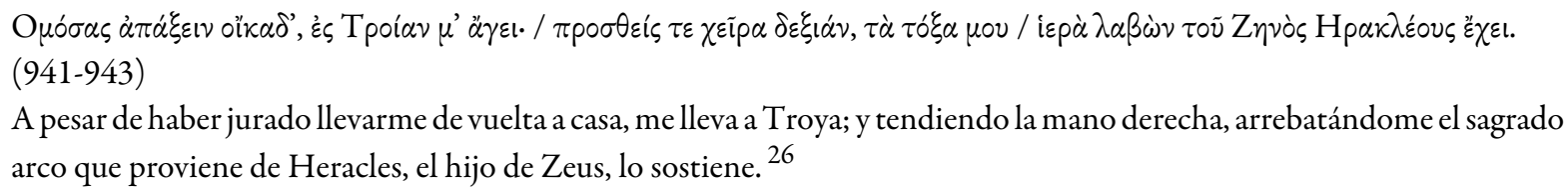

Este pasaje es importante en la medida en que nos ayuda a comprender mejor el origen de la sacralidad del arco. En este punto, llamamos la atención sobre tres aspectos que se pueden poner fácilmente en relación con el contexto religioso y ritual de la época, así como con el contexto dramático en el que aparecen: el juramento, la calificación del arco como "sagrado" y la alusión a tender la mano derecha como garantía. 
Con el fin de obtener el arco, Neoptólemo se presentó como фinos de Filoctetes según las directrices que había dado Odiseo $(585-586,671)$. Estas consistían en transgredir la $\phi i \lambda i ́ \alpha$, un acto a causa del cual Filoctetes se siente traicionado (Heath, 1999, pp. 149-150; Fletcher, 2011, pp. 94-95; Brillante, 2009, pp. 64-66). Pero en este instante el hijo de Peante no menciona la traición a la $\phi i \lambda i ́ \alpha$ sino al juramento que, según Filoctetes, Neoptólemo ha realizado. En cambio, como subraya Fletcher (2011, p. 94), Neoptólemo no ha representado en ningún momento el juramento que le reprocha Filoctetes, sino solo la promesa de no abandonarlo mientras dormía y la exhortación anterior a partir de la isla $(645,810)$. Incluso el hijo de Peante llega a afirmar que no podría ponerlo bajo juramento (810-813). Simplemente, Filoctetes cede el arco a Neoptólemo con el fin de que este lo custodie y lo mantenga a salvo mientras descansa de su herida. ${ }^{27}$ Como explicación del pasaje, Fletcher (2011, pp. 94-95) señala que la mentira de que nos hace partícipes Filoctetes se debe al malentendido entre ambos personajes, que no comprendieron bien el significado del estrechamiento de manos. Esta interpretación reforzaría el éxito que en estos momentos está teniendo el engaño planificado, consistente en presentarse como falsos $\phi \hat{\imath}$ o para conseguir capturar el arco ganando la confianza de su poseedor. Además, de las seis partes de que se compone el juramento, ${ }^{28}$ ninguna de ellas tiene lugar en este instante.

Por otra parte, en el pasaje analizado juega un papel muy importante el lenguaje ritualizado que se refleja en las palabras de Filoctetes, que presentan el juramento como una evocación ritual cuyo formalismo lingüístico entra en el juego dramático. Tal es el caso de la mención a sostener el arco con la mano derecha, inmediatamente después de la alusión al fallido juramento. En este sentido, nos alejamos de los comentarios y seguimos la interpretación de Belfiore (1994, p. 125), que considera la alusión a tender las manos como un gesto ritualizado que tiene como finalidad sostener el arco, gestualidad reforzada por el participio $\lambda \alpha \beta \omega \nu$ y el verbo $\varepsilon^{\prime} \chi \varepsilon l$, cuyo objeto sostenido es precisamente el arco sagrado.

Según esto, la evocación ritual llegaría a tal punto que el juramento se realizaría en el momento en el que Filoctetes coge el sagrado arco entre sus manos $(\lambda \alpha \beta \dot{\omega} \nu)$. A este respecto, conviene recordar que, durante los juramentos, se ponía la mano sobre un objeto sagrado antes de recitar las palabras. Como muestra de ello, Benveniste (1947, pp. 85-86), basándose en testimonios bien documentados, piensa que el término öpkos significaba en un principio el objeto por el que se juraba, que, en el caso de los héroes y los guerreros, solía ser el arma simbólica que los representaba. ${ }^{29}$ Como explica Benveniste, conviene recordar los muchos pasajes de los poemas homéricos en los que se realiza el juramento por la laguna Estigia, que parece encontrarse en aposición al término öpros (Homero, Iliada II.755, XV.37-38; Himno a Apolo 84-85). De un modo similar, Aquiles llama öpros al cetro sobre el que realiza el juramento, tanto Partenopeo como Idas juran por su lanza y Antígona lo hace sobre su espada (Homero, Iliada I.233 y ss.; Esquilo, Los siete contra Tebas 529; Eurípides, Fenicias 1677). Con la misma idea, West (2007, pp. 463-464) ofrece muchos paralelos en otros poemas indoeuropeos, como Las leyes de Manu y el Mahabharata, en los que el guerrero jura por su arma como objeto sagrado y característico del héroe, un nuevo paralelismo entre las armas, los guerreros y la sacralidad. ${ }^{30}$

Otro testimonio aportado por Benveniste (1947, p. 86), que presenta un registro lingüístico similar al que encontramos en Filoctetes, es un pasaje de Esquines, en el que se emplea el mismo participio $\lambda \alpha \beta \omega ́ v$ en alusión al objeto sagrado que se debe sostener entre las manos, en este caso las entrañas, y sobre el que se realiza un

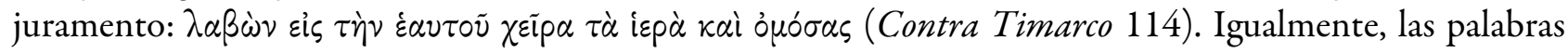
referidas por Filoctetes en el pasaje que analizamos parecen estar reproduciendo un formalismo habitual en la realización del juramento, según el cual un objeto sacralizado debe sostenerse entre las manos con la finalidad de formular las palabras sagradas, que se convierten así en un pacto inamovible e inviolable. ${ }^{31} \mathrm{El}$ contacto físico con el arma, por tanto, es relevante en la medida en que refuerza la sacralidad e inviolabilidad del juramento que, según Filoctetes, ha realizado Neoptólemo.

Pero no podemos acabar este apartado sin mencionar un nuevo paralelismo fácilmente comparable con el juramento al que alude Filoctetes: el juramento de los efebos. Durante el ritual de la efebía, los jóvenes 
atenienses realizaban un entrenamiento militar de dos años que les servía como rito de paso antes de alcanzar la categoría de hoplita (Pélékidis, 1962, pp. 38-39; Vidal-Naquet, 2005, pp. 153-154; Chankowski, 2010, pp. 45-62). Según Harpocración (s. v. $\pi \varepsilon p i ́ \pi 0 \lambda \circ \varsigma$ ), el efebo llevaba a cabo su adiestramiento $\lambda \alpha \beta o ́ v \tau \varepsilon \varsigma \dot{\alpha} \sigma \pi i ́ \delta \alpha$

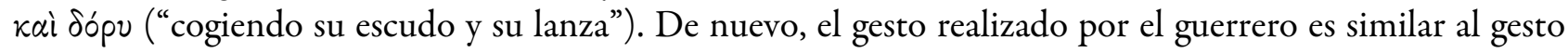
de sostener el arco entre las manos al que alude Filoctetes. Además, durante un momento indeterminado del ritual, los efebos realizaban su famoso juramento, recogido en una estela de Acarnas del siglo IV a. C. reproducida por varios estudiosos (Daux, 1971, pp. 370-371; Siewert, 1977, pp. 102-103; Pélékidis, 1962, pp. 110-113). Durante el ritual, los efebos juraban no deshonrar las sagradas armas ni abandonar al compañero

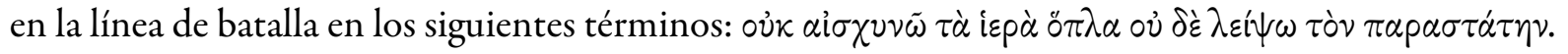

La referencia indirecta al juramento de los efebos no sería extraña si tenemos en cuenta que esta tragedia ha sido comparada en varias ocasiones con el ritual efébico. Según esta interpretación, Neoptólemo, el joven inexperto al principio de la obra, debe realizar un adiestramiento, guiado por su instructor Odiseo, consistente en engañar con palabras al isleño Filoctetes, ganarse su confianza y arrebatarle el arco, con el fin de entrar en la madurez al final de la tragedia. ${ }^{32}$ Por otra parte, entre el juramento de los efebos y el aludido por Filoctetes se produce un paralelismo que los estudiosos han pasado por alto. En el juramento efébico, además de aparecer el valor hoplítico de lealtad al compañero, un valor transgredido en la traición realizada por Neoptólemo, se alude nuevamente a las armas como elemento sagrado (iøpá) al que no se puede traicionar ni deshonrar. Esta inviolabilidad de las armas, que se presentan como simbolismo destacable del hoplita, se encuentra reflejada en las palabras de Filoctetes, que, igual que en el juramento efébico, retoma el mismo epíteto para referirse al arco (iєpá). De este modo, Neoptólemo, cogiendo el arma sagrada e inviolable, ha transgredido los valores que formaban parte del ritual.

El adjetivo i̊pá indica con claridad la importancia de la sacralidad del arco. De hecho, el vocablo se emplea como epíteto de $\tau o ́ \xi \alpha$ en un contexto dramático en el que las palabras reflejan un ambiente ritualizado y sacralizado, donde el arco es el elemento visual más importante. A este respecto, el término recuerda que el

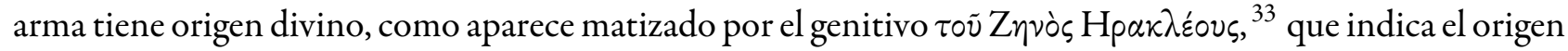

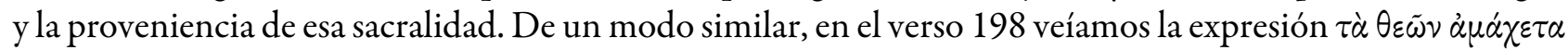
$\beta \varepsilon \lambda \eta$, en la cual el genitivo $\theta \varepsilon \tilde{\omega} \nu$ también señalaba el carácter divino de las armas.

Si tenemos en cuenta la conexión con el ritual efébico, según nuestra interpretación, el hecho de extender las manos se estaría refiriendo al gesto ritualizado de alargar las manos con el fin de sostener el arco; no tanto al estrechamiento de las manos, interpretación ofrecida por los comentarios (Jebb, 1898, p. 152; Kamerbeek, 1980, p. 135). Por otra parte, sería perfectamente plausible la interpretación de los comentarios si comparamos el pasaje con el verso 813, momento en el cual Filoctetes invita a Neoptólemo a tenderle la mano en señal de confianza.

En este verso, se observa con claridad la importancia de sujetar el arco con las manos mediante unos términos que ponen el énfasis en la confianza $(\pi i \sigma \tau \imath)$, que proviene del estrechamiento de manos, como

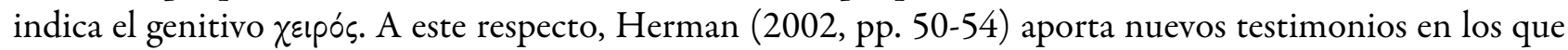
se observa el gesto del estrechamiento de manos, que constituía una parte importante del ritual de la $\xi \varepsilon v i ́ \alpha$ anteriormente analizado. La similitud con otros contextos es tan grande que, en el verso 813, podría tratarse del estrechamiento de manos. ${ }^{34}$ Pero en este momento no se alude al juramento, sino al ritual de la $\xi \varepsilon v i ́ \alpha$, según el cual se ofrecía como intercambio de fidelidad unos regalos de un fuerte valor simbólico, llamados $\pi \iota \tau \alpha^{\prime},{ }^{35}$ acompañados del estrechamiento de manos. La confianza sellada, por tanto, se ritualiza en este caso mediante el estrechamiento y el ofrecimiento del arco como garantía, que Filoctetes debe sostener. Posteriormente, Filoctetes mencionará la traición a un juramento que no ha tenido lugar, sino solo el acto ritualizado que rememora el ritual de la $\xi \varepsilon v i ́ \alpha$. Con todo, como hemos observado, la alusión a tender la mano derecha con el fin de capturar el arco en el mismo verso en el que se menciona el juramento puede recordar, de manera indirecta, el gesto ritualizado de extender la mano derecha para mantener el arma entre las manos. De este modo, en la tragedia se hace especial hincapié en un contacto físico con el arco como elemento simbólico 
importante. Este contacto, a su vez, vincula a ambos personajes por medio de un pacto de mutua e inviolable fidelidad. ${ }^{36}$

Nuestra interpretación aparece constatada por los versos siguientes, en los cuales Neoptólemo es ahora quien cede el arco a Filoctetes en señal de confianza. Así, se resalta nuevamente el elemento visual de sostener el arma entre las manos, por medio de un contacto físico que sirve de mutuo acuerdo entre los personajes. Este pasaje tiene lugar en un momento posterior, en el cual Neoptólemo, siendo consciente de la traición cometida, entrega a Filoctetes el arma en un nuevo pacto de fidelidad legitimado por el gesto ritualizado de sujetar el arco con las manos:

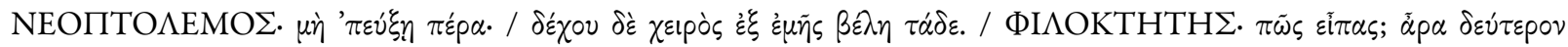

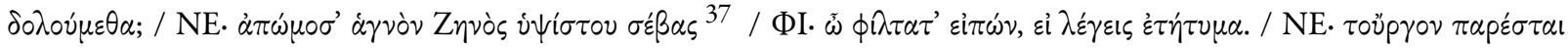

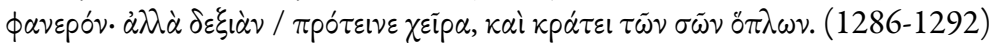

NEOPTÓLEMO: No maldigas más: recibe de mi mano estas flechas. FILOCTETES: ¿Cómo dices? ¿Por segunda vez soy engañado? NE: Lo juro por el respeto puro de Zeus de las alturas. FI: Dices palabras queridas, si dices la verdad. NE: Se presenta visible el hecho: tiéndeme la mano derecha y sostén tus armas.

El retorno del arco a su anterior poseedor provoca la incredulidad de Filoctetes, que pregunta si es nuevamente engañado. Ante las palabras del hijo de Peante, Neoptólemo pone de manifiesto el juramento que en este momento realiza, poniendo como testigo al dios de las alturas. Es a Zeus Horkios a quien se alude, en una conocida esfera de acción de la divinidad como garante de los juramentos. A este respecto, en el verso 1324, Neoptólemo invocará expresamente a esta divinidad como introducción del juramento que el hijo de

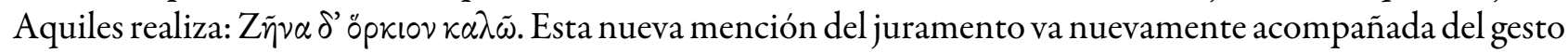
ritualizado de tender la mano derecha en señal de garantía y nuevo pacto de fidelidad. Tras la mención de este gesto, Neoptólemo debe invitar a Filoctetes, de manera expresa, a sostener las armas. Asistimos aquí a un nuevo protocolo ritualizado que conjuga la $\xi \varepsilon v i ́ \alpha$, el juramento y el contacto físico con el arma antes de realizar el juramento.

El registro lingüístico de estos versos reproduce un formalismo que recuerda el pasaje anterior, en el que Filoctetes informaba de la traición al falso juramento y del mismo gesto ritual, consistente en extender la mano derecha y sostener el arma. Este nuevo pasaje confirma nuestra interpretación del texto anterior, en el sentido de que Filoctetes no se refería al estrechamiento de manos sino al gesto ritualizado de extender las manos para sostener el arco y realizar el juramento. Pero si en los versos anteriores asistíamos a una transgresión ritual que conllevaba la traición a la promesa realizada, en este instante se reinstaura la normalidad del ritual mediante un verdadero juramento por medio del cual se reencauzan los valores inviolables de fidelidad y compañerismo.

\section{Conclusiones}

En los cuatro pasajes analizados hemos detectado una serie de elementos que nos inducen a reconsiderar la causa de la sacralidad del arco de Filoctetes. Como vimos en la introducción, los estudiosos coinciden en el hecho de que el motivo de esta sacralidad se encuentra en la relación del arco con Heracles, su anterior poseedor. Los estudios que tratan el tema se limitan a identificar otros elementos rituales presentes en la obra. En nuestra opinión, estos rasgos rituales deben ponerse en relación directa con el origen de la sacralidad del arco. Este, según creemos haber demostrado, es sagrado no solo por su vínculo con Heracles, sino también por formar parte de una tradición a causa de la cual se encuentra asociado con lo divino y lo sagrado. Pero al mismo tiempo, los contextos dramáticos analizados nos hacen considerar que el arco participa de una tradición épica mucho más amplia, que lo conecta con la guerra, los héroes y las divinidades.

Prueba de ello es el hecho de que el arco, como objeto simbólico y visual destacable, aparece en contextos en los cuales hay una fuerte relación con lo épico y lo religioso. Tal es el caso del epíteto $x \lambda \varepsilon\llcorner v o ́ \varsigma$, que, en 
el momento en el que aparece, conecta el arma con la guerra y la divinidad. Dentro de la tragedia, el arco es importante por la función bélica que desempeñará en la guerra contra Troya, recibiendo epítetos como $\dot{\alpha} \mu \dot{\alpha} \chi \varepsilon \tau \alpha$ o $\dot{\alpha} \nu i ́ \kappa \eta \tau \alpha$. Con ello, parece recordarse un elemento importante de las armas, que constituían un símbolo indisociable de los héroes y los guerreros en la batalla. Así sucede con algunos héroes homéricos, como Diomedes o Menelao, que son ilustres gracias a su lanza. También el genitivo plural $\theta \varepsilon \tilde{\omega} \nu$, dependiente de las armas, nos informa que estas son sagradas por su relación con lo divino, del mismo modo que otras armas representativas de héroes homéricos presentan una importante conexión con la divinidad, como las armas de Aquiles o el escudo de Áyax. Como hemos visto, los paralelismos se multiplican, no solo en el mundo griego sino también en otras culturas. Teniendo en cuenta tanto los contextos dramáticos como los aspectos culturales y religiosos de la tradición de Sófocles, consideramos que estas similitudes podrían reflejar que la sacralidad del arco deriva, no solo de Heracles, sino también de todo ese ambiente contextual que relaciona las armas, los guerreros, los héroes y los dioses.

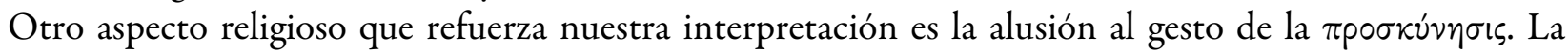
reverencia ante el arco refleja que se trata de un objeto sacralizado y comparado con los dioses, ante cuyas imágenes se realizaba el mismo gesto. Como hemos comprobado, también en otros contextos, como los juramentos de Partenopeo e Idas, los guerreros reverenciaban sus armas, cuya gloria excedía los límites humanos. Igualmente, son recurrentes las referencias al ritual de la $\xi \varepsilon v i ́ \alpha$, según el cual se sellaba un pacto de fidelidad entre dos personas que, con el fin de cesar las hostilidades, se intercambiaban presentes en agradecimiento por la $\varepsilon \dot{\varepsilon \rho} \gamma \varepsilon \sigma i ́ \alpha$ realizada. El contacto físico con el arma como símbolo sagrado juega un papel muy importante en el ritual, ya que de este modo se realiza un pacto inviolable sobre un objeto cargado de un fuerte valor simbólico y religioso, entrando en contacto directo con lo sagrado.

Un elemento ritualizado importante es la alusión al falso juramento que menciona Filoctetes. Con ello, se refleja una transgresión ritual basada en la traición ante un elemento tan sagrado como el arco. En este contexto, es relevante la evocación de la gestualidad consistente en sostener el arco entre las manos y pronunciar las palabras del juramento, que aún no se ha llevado a cabo. Esta interpretación, pasada por alto por los estudiosos, se refuerza mediante la comparación con otros contextos en los cuales se debía poner las manos sobre un objeto importante por el que se realizaba el juramento. Nuestra interpretación se encuentra corroborada por el último pasaje estudiado, cuyo formalismo lingüístico refleja similitudes con el texto anterior, en la idea de que para realizar el juramento se pide al destinatario que extienda la mano derecha con el fin de sostener las sagradas armas y entregárselas en señal de mutua confianza. Al mismo tiempo, consideramos importante la relación entre el juramento de los efebos y el referido por Filoctetes, pues en ambos casos se mencionan valores similares, transgredidos en la tragedia, y se alude a las armas como objeto sagrado al que no se debe deshonrar en el caso de los efebos y ante el cual se ha realizado un supuesto juramento traicionado en el caso de Filoctetes. Con todo, aunque las palabras de Filoctetes reflejan simplemente que Neoptólemo realizó un juramento de fidelidad y lo traicionó arrebatándole las armas, el registro lingüístico podría recordar la misma gestualidad que encontramos en otros contextos en los que se realizaba un juramento.

Las comparaciones realizadas confirman la importancia del arco como elemento sagrado en la tragedia Filoctetes. Como hemos podido comprobar, esta sacralidad no solo se explica por la procedencia heraclea del arco, sino también por la relación que, tanto en el mundo griego como en otras culturas y en los contextos dramáticos analizados, tenían las armas entre los héroes, la guerra y las divinidades. Estas relaciones conferían a las armas cierto carácter sagrado, pues procedían de los dioses y, en el plano simbólico, se convertían en reflejo del héroe en el campo de batalla.

\section{REFERENCIAS}

Austin, N. (2011). Sophocles' Philoctetes and the great soul robbery. Madison: University of Wisconsin Press. 
Belfiore, E. (1994). Xenia in Sophocles' Philoctetes. CJ, 89(2), 113-129.

Belfiore, E. (2000). Murder among friends: violation of philia in Greek tragedy. Oxford: Oxford University Press.

Benveniste, E. (1947). L'expression du serment dans la Grèce ancienne. RHR, 134, 81-94.

Biggs, P. (1966). The disease theme in Sophocles' Ajax, Philoctetes and Trachiniae. CPh, 61, 223-235.

Bollack, J. (1958). Styx et serments. REG, 71, 1-35.

Brillante, C. (2009). Filottete: elementi tradizionali, riprese e innovazioni sofoclee. QUCC, 93, 49-77.

Brook, A. E. (2014). Ritual poetics in the plays of Sophocles (tesis doctoral). University of Toronto, Toronto, Canadá. Recuperada de https://search.proquest.com/docview/1666453089?pq-origsite=gscholar

Burkert, W. (2007). Religión griega: arcaica y clásica. Madrid: Abada Editores.

Chankowski, A. S. (2010). L'éphébie hellénistique: étude d'une institution civique dans les cités grecques des îles de la mer Égée et de l'Asie Mineure. Paris: De Boccard.

Daux, G. (1971). Le serment des éphèbes athéniens. REG, 84, 370-383.

Dumézil, G. (1948). Mitra-Varuna: essai sur deux représentations indo-européennes de la souveraineté. Paris: Gallimard.

Easterling, P. E. (1978). Philoctetes and modern criticism. ICS, 3, 27-39.

Fletcher, J. (2011). Performing oaths in classical Greek drama. Cambridge: Cambridge University Press.

Fletcher, J. (2013). Weapons of friendship: props in Sophocles' Philoctetes and Ajax. En G. W. M. Harrison \& V. Liapis (Eds.). Performance in Greek and Roman Theatre. Mnemosyne Supplements. Monographs on Greek and Latin Language and Literature, 353 (pp. 199-215). Leiden-Boston: Brill.

Gill, C. (1980). Bow, oracle and epiphany in Sophocles' Philoctetes. G\&R, 27(2), 137-146.

Harrison, J. (1989). Sophocles and the cult of Philoctetes. JHS, 109, 173-175.

Harsh, P. W. (1960). The role of the bow in the Philoctetes of Sophocles. AJPh, 81(4), 408-414.

Heath, M. (1999). Sophocles' Philoctetes: a problem play? En J. Griffin (Ed.), Sophocles revisited: essays presented to Hugh Lloyd-Jones (pp. 137-159). Oxford: Oxford University Press.

Herman, G. (2002). Ritualised friendship and the Greek city. Cambridge: Cambridge University Press.

Hinds, A. E. (1967). The prophecy of Helenus in Sophocles' Philoctetes. CQ, 17(1), 169-180.

Kaimio, M. (1988). Physical contact in Greek tragedy: a study of stage conventions. Helsinki: Suomalainen Tiedeakatemia.

Knox, B. M. W. (1964). The heroic temper: studies in Sophoclean tragedy. Berkeley-Los Angeles-London: University of California Press.

Kosak, J. C. (1999). Therapeutic touch and Sophocles' Philoktetes. HSPh, 99, 93-134.

Lada-Richards, I. (1997). Neoptolemos and the bow: ritual thea and theatrical vision in Sophocles' Philoctetes. JHS, 117, 179-183.

Lada-Richards, I. (1998). Staging the ephebeia: theatrical role-playing and ritual transition in Sophocles' Philoctetes. Ramus, 27(1), 1-26.

Lasso de la Vega, J. (2003). Sófocles. Madrid: Ediciones Clásicas.

Mauduit, C. (1995). Les morts de Philoctète. REG, 108(2), 339-370.

Mazzeo, M. (2014). Ci metto la mano sul fuoco: ordalia, maledizione, giuramento. RIFL, 8(2), 284-297.

Morillo, S. R. (1995). El simbolismo del arco de Odiseo. Gerión, 13, 27-45.

Naiden, F. S. (2006). Ancient supplication. Oxford: Oxford University Press.

Pélékidis, C. (1962). Histoire de l'éphébie attique des origines à 31 avant Jésus-Christ. Paris: Editions E. de Boccard.

Pleket, H. W. (1981). Religious history and the history of mentality: the 'believer' as a servant of the deity in the Greek world. En H. S. Versnell (Ed.), Faith, hope and worship (pp. 152-192). Leiden: Brill.

Sage, M. (1996). Warfare in ancient Greece: a sourcebook. London: Routledge.

Seaford, R. (1994). Reciprocity and ritual: Homer and tragedy in the developing city-state. Oxford: Clarendon Press. 
Segal, Ch. (1976). Divino e umano nel Filottete di Sofocle. QUCC, 23, 67-89.

Segal, Ch. (1980). Visual symbolism and visual effects in Sophocles. CW, 74(2), 125-142.

Segal, Ch. (1999). Tragedy and civilization: an interpretation to Sophocles. Norman: University of Oklahoma Press.

Segal, Ch. (2013). El mundo trágico de Sófocles. Madrid: Gredos.

Siewert, P. (1977). The ephebic oath in fifth century Athens. JHS, 97, 102-111.

Snodgrass, A. M. (1991). Armi ed armature dei Greci. Roma: L'Erma di Bretschneider.

Taplin, O. (2003). Greek tragedy in action. London: Routledge.

Vidal-Naquet, P. (2002). El Filoctetes de Sófocles y la efebía. En J. P. Vernant \& P. Vidal-Naquet (Eds.), Mito y tragedia en la Grecia antigua (pp. 163-190). Barcelona: Paidós.

Vidal-Naquet, P. (2005). Le chasseur noir. Paris: Éditions La Décuverte.

West, M. L. (2007). Indo-European poetry and myth. Oxford: Oxford University Press.

\section{EDICIONES Y COMENTARIOS}

Avezzù, G., Pucci, P. \& Cerri, G. (Eds.). (2003). Sofocle: Filottete. Introduzione e commento di P. Pucci; Testo critico di G. Avezzú; Traduzione di G. Cerri. Milano: Arnoldo Mondadori Editore.

Jebb, R. C. (Ed.). (1898). Sophocles: The plays and fragments. The Philoctetes. Vol. 4. Cambridge: Cambridge University Press.

Kamerbeek, J. C. (Ed.). (1980). The plays of Sophocles: The Philoctetes. Leiden: Brill.

Lloyd-Jones, H. \& Wilson, N. G. (Eds.). (1990). Sophoclis fabulae. Oxford: Oxford University Press.

Schein, S. L. (Ed.). (2014). Sophocles: Philoctetes. Cambridge: Cambridge University Press.

Webster, T. B. L. (Ed.). (1970). Sophocles: Philoctetes. Cambridge: Cambridge University Press.

\section{Notas}

* Fernando Pérez Lambás es doctor en Filología Griega por la Universitat de València (2017). Se licenció en Filología Clásica (2010) con premio extraordinario en la misma Universidad. Obtuvo el doctorado en 2017 con una tesis sobre los Elementos rituales en los prólogos de Sófocles. Su línea de investigación se centra en la tragedia griega, concretamente en Sófocles y los prólogos trágicos, pero también en tradición clásica y religión griega. Tiene varios artículos y publicaciones científicas, entre las que destacan: "El prólogo y el primer estásimo de Edipo en Colono: un estudio comparativo" (Cuadernos de Filología Clásica. Estudios griegos e indoeuropeos, 27, 2017, pp. 49-63); “Técnica teatral y paradojas en los prólogos de Sófocles" (Minerva: revista de Filología Clásica, 31, 2018, pp. 35-60); Los elementos rituales en las tragedias de Sófocles. Tipología y función a partir de los prólogos (Amsterdam: Adolf M. Hakkert, 2018); El mito de Fedra en Séneca, Racine y Unamuno (Mauritius: Editorial Académica Española, 2018).

1 Es bien sabido que Áyax, como héroe épico, representa unos valores que no tienen cabida en la nueva sociedad ateniense. El objeto visual que concentra este cambio es la espada, que acaba destruyendo el valor heroico de Áyax cuyos ideales forman parte ahora de un contextoo distinto. Sobre esto, vid. Segal (1999, pp. 116-117).

2 Aunque el vaticinio de Héleno menciona solo que se debe llevar a Troya a Filoctetes (vv. 610-613), para Odiseo parece que solo el arco es importante (v. 113). En cambio, al final de la tragedia Heracles predice el destino de Filoctetes en su partida hacia Troya, dejando claro que tanto el hijo de Peante como su arco son necesarios para poder conquistar la ciudad (vv. 1423-1430). Sobre esto, vid. Hinds (1967, pp. 170-180); Knox (1964, pp. 126-127); Gill (1980, pp. 140-141).

3 Por otra parte, no debemos olvidar que el arco, en la época de Sófocles, era un símbolo guerrero ambivalente. Así, representaba la cobardía de los bárbaros, símbolo de los persas en las guerras médicas y de Paris en la guerra de Troya, y al mismo tiempo era el emblema de héroes ilustres como Odiseo o Heracles. Sobre esto, vid. Morillo (1995, p. 27); Brook (2014, p. 196, n. 518); Sage (1996, p. 90).

4 Segal (1980, p. 132) pone de manifiesto la importancia del arco como objeto heroico sagrado, cuya heroicidad se remonta al pasado. Con todo, este estudioso analiza el objeto como símbolo visual esencial y deja de lado la relación con el contexto religioso y épico. 
5 Como sustento de la vida del personaje y arma que sirve a Filoctetes para cazar, podría verse en el arco un símbolo de la superioridad del hombre frente a las bestias del mundo incivilizado, como piensa Harsh (1960, p. 412).

6 Sobre esta imagen tan presente en la tragedia, remitimos a los estudios de Biggs (1966), Knox (1964) y Mauduit (1995) citados en la bibliografía.

7 Recuérdese a este respecto que la ő ıs es, según Aristóteles (Poética 1450a 10), una de las seis partes constitutivas de la tragedia.

8 Homero, Iliada II.716-725; Diodoro Sículo IV.38; Sófocles, Filoctetes 262, 1406. Sobre esto, vid. Morillo (1995: 38).

9 Cf. Schein (2014, p. 264); Lasso de la Vega (2003, p. 162); Jebb (1898, p. 152); Segal (1999, p. 321); Kamerbeek (1980, p. 135); Snodgrass (1991, p. 82); Avezzù, Pucci \& Cerri (2003, p. 269); Fletcher (2013, p. 207).

10 Para el texto en griego seguimos la edición de Lloyd-Jones \& Wilson (1990) citada en la bibliografía. Todas las traducciones son personales.

11 Cf. Homero, Iliada V.45, V.55, V.578, X.230, XI.333, XI.396, XIII.210, XIII.467, XIII.476, XVI.26, XXI.233; Odisea

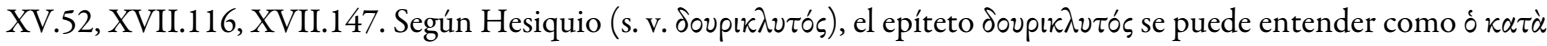

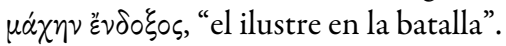

12 También se podría pensar que la calificación del arco como $\kappa \lambda \varepsilon \imath v o ́ \varsigma$ es simplemente un modo de aludir a la fama que tenían tanto Filoctetes como el objeto. En el momento de la aparición del arco, Neoptólemo estaría llamando la atención sobre el objeto por el cual Filoctetes es conocido. Con todo, la estrecha unión entre Filoctetes y su arma, así como la finalidad heroica que ambos persiguen marchando a Troya, nos induce a considerar que deberíamos explicar este epíteto por las resonancias épicas y guerreras que tiene.

13 Sobre esto, vid. Morillo (1995, pp. 38-39). En el artículo citado, Morillo pone de manifiesto las concomitancias entre el arco de Odiseo y el de Heracles. En su estudio, llega a afirmar que ambos héroes poseen arcos que tienen carácter divino: sus respectivos arcos provienen del dios Apolo, se utilizan para sellar relaciones de dependencia y fidelidad y se requieren como talismanes protectores necesarios para obtener la victoria, sobre Troya en el caso de Heracles y sobre los pretendientes en el de Odiseo.

14 Por otra parte, el origen heracleo de las armas de Filoctetes era un hecho bien conocido por el espectador, pues dentro de la misma tragedia los personajes mencionan de manera explícita que las armas provienen de Heracles, vid. Sófocles, Filoctetes 262, 1406.

15 Según Heródoto, los escitas adoraban al dios de la guerra en forma de cimitarra (Heródoto IV.62.2), una clara asociación entre el arma del guerrero y la divinidad. Encontramos también otras anécdotas transmitidas por Acusilao (FGrHist. 2 F 22), Virgilio (Eneida X.773) y Estacio (Tebaida III.615, IX.549), entre otros. Dentro del mundo indoiranio, encontramos muchos ejemplos que corroboran el carácter divino de las armas de los guerreros, como el carro de Indra fabricado por artesanos divinos (RigVeda 8.77.11), o las armas gloriosas de Mitra (Yt. 128-129, 141). También hallamos paralelos en la mitología irlandesa, donde se describe la coraza de CúChulainn fabricada con siete pieles de buey (Táin(I) 2219-2221), y en las armas de Beowulf (Beowulf 455), así como en la mitología nórdica, donde además del famoso martillo de Thor aparecen muchas armas divinas construidas por enanos. Sobre esto, vid. West (2007, pp. 460-464); Dumézil (1948, p. 138).

16 Según Lada-Richards (1997, pp. 180-182), la visión del arco sagrado podría recordar la visión sagrada de los iniciados en los misterios de Eleusis. Lo mismo sucedería con los calificativos ő $\sigma \iota$ y $\theta \varepsilon ́ \mu \iota$, que se podrían estar refiriendo a los misterios eleusinios en un lenguaje que haría referencia a los iєpá revelados por el hierofante.

17 Sobre este ritual, vid. Herman (2002, p. 50); Belfiore (2000, pp. 64-65).

18 Filoctetes considera enemigos a los griegos que lo arrojaron impíamente (257) a la desértica isla de Lemnos, concretamente a Odiseo y a los Atridas, a quienes califica varias veces como ż $\chi$ poí $(460,1376-1377,1386)$ y como $\pi \alpha \nu \omega \dot{\nu} \varepsilon \theta$ po (322). Por otra parte, desde el primer momento Filoctetes siente una gran curiosidad y deseo por escuchar la anhelada voz de los griegos, que habitan el mundo civilizado. Así, el personaje califica la voz de Neoptólemo como $\phi i \lambda \tau \alpha \tau \circ \nu \phi \omega \dot{\nu \eta \mu \alpha}(225,229,234)$.

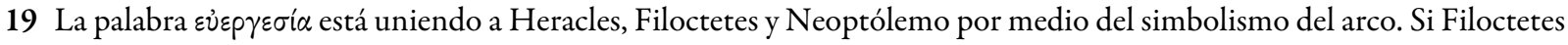

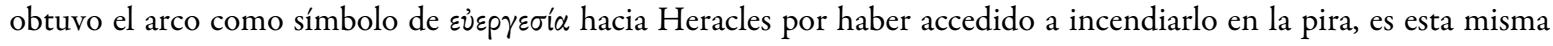

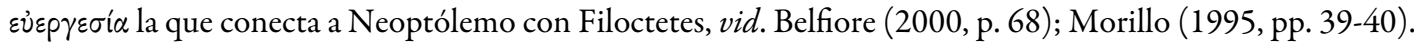

20 Filoctetes llega incluso a invocar al arco como "el arco de la amistad" (1128).

21 Con esta idea, Orestes pide a Pílades que se postre ante la imagen de los dioses en un acto de respeto religioso y Temístocles realiza una reverencia ante el rey de los persas, cf. Sófocles, Electra 1374-1375; Plutarco, Temistocles 28 1-29 2.

22 Igual que el arma, la tierra donde vive Filoctetes debe ser reverenciada antes de partir mediante el gesto de la $\pi \rho \circ \sigma \kappa v ́ v \eta \sigma \iota \varsigma$, pues se trata también de un espacio sacralizado, Sófocles, Filoctetes 533, 1408. Sobre esto, vid. Austin (2011, p. 106).

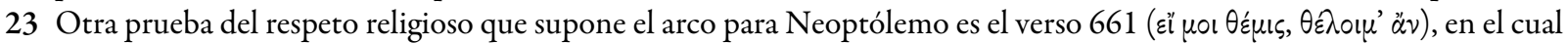
el hijo de Aquiles reconoce al de Peante su deseo por capturar el arco siempre que lo permitan las leyes religiosas ( $\theta \varepsilon \dot{\mu} \mu \varsigma)$. Sobre este pasaje, vid. Austin (2011, pp. 106-107). 
24 Cf. Heródoto 1.32.1; Esquilo, Agamenón 904, Prometeo 936; Píndaro, Ístmicas 7.39; Sófocles, Electra 1466; Platón, República 451a.

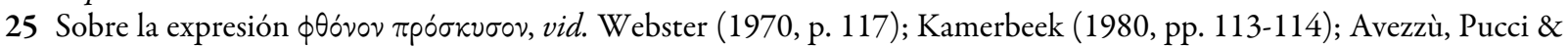
Cerri (2003, p. 249).

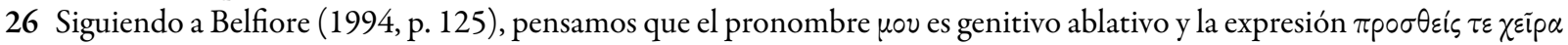
$\delta \varepsilon \xi ı \alpha$ se refiere propiamente a tender la mano hacia delante para sostener el arco. De este modo no estaríamos ante un estrechamiento de manos, sino que el hecho de tender la mano estaría aludiendo al contacto físico con el arco, que es el gesto importante del ritual según el cual Neoptólemo había prometido no abandonar al compañero. Así pues, nos distanciamos en nuestra traducción de las interpretaciones ofrecidas por Jebb (1898, p. 152) y Kamerbeek (1980, p. 135). En cualquier caso, como subraya Belfiore, la frase es ambigua, pues debido a la alusión al juramento podríamos pensar que la expresión se refiere también al estrechamiento de manos, gesto al que se alude de manera clara en el verso 813 y que acompañaba el ritual en otros contextos (cf. Eurípides, Medea 21-22, 495-496).

27 Sobre las finalidades terapéuticas del contacto físico con el arco, vid. Kosak (1999, pp. 99-100).

28 Seguimos la clasificación ofrecida por Fletcher (2011, pp. 4-11).

29 La interpretación de Benveniste ha sido puesta en duda por algunos estudiosos, como Bollack (1958, pp. 33-35) o Mazzeo (2014, pp. 294-295), que, siguiendo a los lexicógrafos griegos, consideran que el vocablo ópros debe ponerse en relación con épкos ("barrera”).

30 En Las leyes de Manu 8.113, un ksatriya, casta perteneciente a los guerreros de la religión hindú, debe jurar por su carro y sus armas. Algo similar sucede en Mahabharata 5.73.14. También en la mitología celta el héroe CúChulainn jura por escudo y su espada, vid. West (2007, p. 464).

31 En palabras de Burkert (2007, p. 336), "al que presta el juramento se le dan en mano las vísceras (...) para hacer tangible su contacto con lo sagrado".

32 Esta interpretación parte mayormente de los estudios de Vidal-Naquet (2002, pp. 171-172) y Lada-Richards (1998, p. 18) y tiene en cuenta aspectos de la obra como el hecho de que el personaje, igual que los efebos, realiza su entrenamiento en un espacio limítrofe entre el mundo civilizado e incivilizado (la cueva) en el que las palabras de Odiseo reflejan

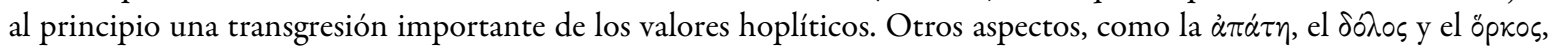
jugaban también un papel importante en el ritual efébico.

33 Según Kamerbeek (1980, p. 135), este genitivo puede depender de ípá o, como genitivo posesivo, de $\tau$ ół $\alpha$. En el primer caso el genitivo indicaría que las armas son consagradas a Heracles y en el segundo ejemplo se referiría a que el arco perteneció al héroe y, por tanto, procede de él. Sobre este pasaje, vid. Schein (2014, p. 264); Avezzù, Pucci \& Cerri (2003, p. 269). El hecho de que el arco sea un objeto sagrado, como señala Seaford (1994, pp. 394-395), también podría estar recordando la importancia que tenía el arco en el culto colectivo de Filoctetes en Crise. Sobre este culto, que no podemos comentar debido a las limitaciones del trabajo, se puede consultar el artículo de Harrison (1989) citado en la bibliografía final.

34 Entre otros contextos estudiados por Herman (2002, pp. 1-2), encontramos Homero, Ilíada VI.224ss., pasaje en el cual se sella un pacto de confianza entre Diomedes y Glauco, y Jenofonte, Helénicas4.1.28-31, en el que Farnabazo y Agesilao se intercambian regalos para fijar su pacto de fidelidad.

35 Sobre estos $\pi \iota \tau \dot{\alpha}$, vid. Herman (2002, p. 50); Belfiore (1994, pp. 115-116, 2000, p. 64). Además, el término $\pi i ́ \sigma \tau \iota v$ del verso 813 recuerda también los versos 70-71, en los que Odiseo daba instrucciones a Neoptólemo de que obtuviera un trato de confianza ( $\left.\delta \mu \imath \lambda i ́ \alpha . . . \pi \imath \tau \eta^{\prime}\right)$ hacia Filoctetes. En el verso que analizamos se observa la consecución de este objetivo.

36 Sobre otros ejemplos trágicos de pactos sellados mediante el contacto físico, vid. Kaimio (1988, pp. 29-34).

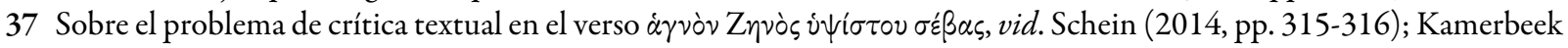
(1980, p. 172); Avezzù, Pucci \& Cerri (2003, p. 303). 